\title{
THE PHENOMENON OF CONSCIOUSNESS FROM AN INTER AND MULTIDISCIPLINARY PERSPECTIVE
}

\author{
Ecaterina Lozovanu*, ORCID ID: 0000-0002-5722-1600, \\ Cristina Lazariuc, ORCID ID: 0000-0003-0585-1675
}

Technical University of Moldova, 168 Ștefan cel Mare Blvd., Chișinău, Republic of Moldova

*Corresponding author: Ecaterina Lozovanu, ecaterina.lozovanu@ssu.utm.md

\begin{abstract}
Contemporary science, in recent decades, reflects intensely on the phenomenon of consciousness. This fact is due to the accelerated development of cognitive sciences, biological and physical sciences, neuroscience, which have achieved certain successes in researching the problem of mind-body, consciousness. However, what is strictly required is the issue of the possibility of a scientific theory of consciousness, which would apply a new research methodology. The most recent approaches in this direction substantiate the need for research from a phenomenological structural perspective, which explains consciousness as a phenomenon determined by the subquantum level. Structural-phenomenological theory holds that this level is a profound reality regulated by specific principles and laws that make consciousness possible.
\end{abstract}

Keywords: consciousness, conscious, Computer Sciences, Cognitive Sciences, theory of information integration, Turing machine.

Rezumat. Știința contemporană, în ultimele decenii, reflectă intens asupra fenomenului conștiinței. Acest fapt se datorează dezvoltării accelerate a științelor cognitive, științelor biologice și fizice, neuroștiințelor, care au obținut anumite succese în cercetarea problemei minte-corp, conștiință. Totuși, ceea ce se cere strict este problema posibilității unei teorii științifice a conștiinței, care să aplice o nouă metodologie de cercetare. Cele mai recente abordări în această direcție fundamentează necesitatea cercetării dintr-o perspectivă structurală fenomenologică, care explică conștiința ca fenomen determinat de nivelul subcuantic. Teoria structural-fenomenologică susține că acest nivel este o realitate profundă reglementată de principii și legi specifice care fac posibilă conștiința.

Cuvinte cheie: conștiință, conștient, Informatică, Științe cognitive, teoria integrării informației, mașină Turing.

\section{Introduction}

One of the main concepts of philosophy, from antiquity to the present day, is consciousness - which means the faculty of the mind to react to external and internal stimuli, to make knowledge possible. Problems related to consciousness in philosophy have always 
referred to how a subject can become the object of his own observation and whether any mental state is necessarily accompanied by consciousness. In contemporary philosophy the concept of consciousness is used with the following meanings: one of the meanings refers to self-knowledge (introspection), another meaning highlights a general property of mental states (cognition) and a third retains a hedonistic or utilitarian meaning, and moral sense, i.e. the ability to qualify an action as moral or immoral.

The theme of "consciousness" has become extremely important for science, technology, contemporary philosophy, and this is due to the accelerated development of Computer Science and Artificial Intelligence (Al). Based on these, some researchers support, from a methodological perspective, the assertion that consciousness is a specific physical process of the brain. Others believe that it is beyond the physical and cannot be revealed by current science, and can be known by an extended future science. This type of confrontations obviously has a philosophical dimension, related to establishing the nature of consciousness.

The great discoveries of the twentieth century such as: relativity, Quantum Mechanics, Genetic Biology, Neurophysiology, Computer Science, Artificial Intelligence are the reasons why consciousness has become one of the main concerns of science. However, the attempts to scientifically explain consciousness have so far failed. As a result, it was concluded that the problem of consciousness involves an effort in which various sciences must participate (Physics, Biology, Psychology), but also philosophical and theological thinking. The concept of "consciousness" is in the spotlight today due to the problems that have arisen in a new type of science: Computer Sciences and Cognitive Sciences.

Inter and multidisciplinary research and theories of the phenomenon of consciousness

Cognitive sciences, in close connection with cybernetics and Al, have given rise to new philosophical problems and approaches. Cybernetics, as a science, was achieved due to the study of thought patterns and of human action principles, which were mathematized. The cognitive sciences, in their evolution, have moved from the mathematical models and cyber languages of $\mathrm{Al}$ to models that reflect the functioning of the mind and the connection with the physical in the case of human consciousness. Today, in the cognitive sciences, the neural approach is being developed and it draws a parallel between computer programs and brain processes, finding that neurobiological research on the brain can lead to results that would facilitate the explanation of mental and conscious phenomena. This approach reveals divergences between those who consider consciousness to be a limit of science and those who claim that it is the object of scientific knowledge.

The theory of identity between mind and brain considers consciousness a mental phenomenon produced by the brain. In this way the dualism between consciousness and matter is excluded, but the problem related to the capture of the quality (feelings) of consciousness, of its qualitative specificity that remains ineffable, is preserved. To claim that statements about consciousness are statements about brain processes is obviously false. In the direction of avoiding reductionist materialism, the idea of consciousness without corporeality is supported. Proponents of this concept make an extension of the forms of consciousness compared to the theory of identity, and the limits of the possibility of explanation do not come from the specific quality of consciousness but from the intersection of philosophical interpretations with scientific approaches. Thus, it is found that consciousness is the main point that separates Philosophy in various currents, Psychology in different directions, materialism of idealism, reductionism of holism, behaviorism of 
introspectionism. At the current stage, divergences persist between conceptions of $\mathrm{Al}$ in the strongest sense, which support the possibility of making a robot with emotions and consciousness, and those that, distinguishing consciousness from conscious, believe that computer programs will simulate conscious (reactions to stimuli, integration of information, reportability of mental states, access to one's own states), but not in any form consciousness.

Among the contemporary researchers dealing with the problem of consciousness, we can nominate Roger Penrose, an illustrious physicist and mathematician who excelled in the fields of $\mathrm{Al}$ and Philosophy. He does not support the exaggerated optimism that the computer will be able to do everything the human mind achieves. Penrose also speaks out against the physical reductionism according to which the machine, Al and the brain operates on the basis of physical laws, which can be known. Penrose supports the reality of Mandelbrot's fractal structures and the incompleteness of quantum mechanics, supported by Al. Einstein. Addressing the issue of the possibility of the computer to have a mind and sentimental experience, Penrose inevitably reaches philosophy, especially the research of the relationship between physical and electronic structures and the nature and functions of consciousness. He pointed out that to understand these things one needs neurophysiological knowledge of the brain, its computer models and the status of Al (with the structure of the Turing machine, Godel's theorem and the theory of complexity). At the same time, it is supported the need to know the fundamentals of mathematics and the nature of physical reality.

It is known that any automation by definition is unconscious and it is difficult to implant parts that simulate consciousness. The Turing machine was designed to try something like this. However, it has elements that are programs and not activities of consciousness. It is possible to admit that some computers are aware of the programs of other computers but, "it remains unconscious in its" hard "part, as well as the brain that determines conscious, remaining itself unconscious" [1]. Consciousness is necessary to have common sense, understanding, judgment of truth and it is not necessary in programmed, algorithmic thinking. Aristotle's syllogism, Boolean's symbolic logic, the computer program can be applied without being aware of their own production process. Penrose argues against the idea that the development of computer algorithms will be able to simulate the human mind. He argues that a computer cannot function in analogy with the conscious mind, even if some aspects of its activity may be captured by computational processes. The problem of the whole human being, endowed with consciousness, goes beyond the computer.

Regarding the problem of locating consciousness in the brain, Penrose argues that even conscious is not correlated with the activity of a part of the brain. However, some neurophysiologists claim that there is a localization of consciousness in the reticular formations of the brain which, in the event of their destruction, consciousness is lost. Another issue of great importance, addressed by Penrose, is the connection between conscious and language. Language has centers in the brain with location in the left hemisphere, and this would support the idea of the location of conscious. According to Penrose, we cannot find a specific place in the brain where conscious is produced, it has "uniqueness" due to the fact that like the quantum state it is produced by existing parallel processes" [2]. Therefore, for the "conscious mental state" the quantum effects that can appear in the activity of the brain are relevant.

Another issue of major importance, addressed by Penrose, is the role of consciousness in relation to the Universe as a whole, referring in this case to the anthropic principle. According to this principle, the laws of evolution of the Universe lead to the appearance of 
the conscious being - man, who has a location in space-time. He claims that this principle has a useful aspect, but that there are other perspectives to explain the evolution of the conscious being such as: the theory of quasi-crystals and quantum gravity.

At the same time, the scientist claims that consciousness is a biological form that involves intentionality that can be thought of as a digital computer with aspects that cannot be captured by the algorithm. There are elements of thinking that cannot, in principle, compete with the computer. Research into special areas of Physics such as complex numbers, black holes, entropy, quasicrystals, brain structure, and the physical processes of consciousness leads Penrose to support the essential role of Quantum Mechanics in the structure of mind operations, but also to assume that there are deeper levels of determining consciousness, but all being limited by the ineffability of this spiritual reality.

A distinct conception in this direction is produced by David Papineau, who represents the philosophy of naturalistic realism. In the opinion of the English philosopher, the notion of "naturalism" represents various meanings: 1) philosophy is a continuity of the empirical sciences; 2) nonacceptance of mind / body dualism and epistemological internalism. A physicalist conception is supported, according to which two systems are physically identical, if they are biologically, chemically, psychologically identical. Thus, it is stated that mental phenomena are determined by physical phenomena, and the "substance" of the mind is, in a sense, the same as the physical substance.

Papineau argues that there are no reasons for a dualistic conception and speaks out against those who claim that consciousness is "a mysterious inner light" without physical properties. Consciousness has a complex, superior form of organization that is physical in nature. Thus, the most effective procedure for explaining consciousness is the naturalistic one, according to which the human being is part of the natural world described by science.

Another researcher who, in his work, addressed the issue of consciousness is John Rogers Searle. He developed a comprehensive theory of language, arguing that consciousness and intentionality are biological processes caused by neural processes. In his position on the cognitive sciences, which promised a break with behaviorism, Searle argues that a computational theory of mind cannot be founded because human knowledge cannot be reduced to empiricism because it has a special dimension - consciousness. The central question Searle is concerned with is how to link unconscious states (beliefs, desires) to consciousness. Searle's answer involves the principle called "connection" which states that "there is an oppositional configuration of unconscious states due to which they are brought to consciousness. There is a neurological basis, a background with unconscious states and processes, but which produce conscious ideas and actions" [3].

According to John Searle, with reference to consciousness, Analytical Philosophy produced behaviorist and functionalist orientations supported by the cognitive sciences. Through this, the mental was harmed because the Analytical Philosophy characterized it as possessing some mysterious and occult characteristics. Analytical Philosophy preserves the behaviorist perspective in the problem of consciousness and requires the verification of sentences about consciousness in the observation of human behavior. We find the same shortcomings in the interpretation of functionalism, supported by physicalism, which accepts the theory of identity of mental states with neurophysiological ones. Functionalism excludes the irreducible properties of consciousness and tries to define it through causal (mechanical) relations. At the present stage, organic functionalism has developed based on the analogies of the Turing machine, according to which mental states are not functional states but logical 
states of the computer, and mental processes are described as computational processes handled by cognitive sciences and artificial intelligence In his work, Searle reveals the confusion inherent in functionalist guidelines regarding the possibility of clarifying what a mental state is and how such a state is attributed to a person. Another mistake is methodological in nature and refers to the thesis that the cognitive sciences and the computer would allow knowledge of mental operations. That is, it is considered that the philosophical problems of consciousness can be transformed into technical and scientific problems. This is false, because computer programs cannot in themselves be the cause of the biochemical effects of the brain, and man can install programs without having relevant mental states. According to Searle, the nonacceptance of the metaphysical elements behind the scientific aspects of mental states gives rise to false aspects in the mind-body problem and of consciousness in general.

In general, we can say that, despite a series of impediments, some progress has been made in researching the way the brain works, the way it perceives, feels. This allows us to argue that today there are enough intellectual resources to master the power of the brain, to direct the mind and consciousness. So far, there are many approaches to consciousness, but what is strictly necessary is the question of the possibility of a scientific theory of consciousness and how to substantiate it. It is in the interest of mankind to develop a science of consciousness.

The main investigations, which have achieved certain successes, in the research of the mind-body problem and of consciousness, have been carried out in the fields of Biological and Physical sciences: quantum theory, global space theory, computational and informational theory, life and consciousness theory from the perspective of Biophysics and Medicine; in Philosophy: on the concepts of qualia, explanation, intentionality, free will, from an ontological and epistemological point of view; in Cognitive science and Psychology: the theory of cognitive models, the theory of integrated information, the theory of artificial intelligence; in Neuroscience: the theory of neurons and neural correlates, the functionalist theory. Recently, a number of theories have been added such as: the theory of higher perception and thinking, the theory of integrated information.

According to higher order theory, a perception or a thought does not become conscious unless they are the intentional object of a higher order mental state. That is, a perception becomes conscious only when a higher thought contains it. In this way, consciousness has a rational character between the lower and upper levels of the brain. As D. Dennet points out, "the brain is an extremely complicated machine, so mental states are the result of a dynamic process that takes place on several tracks, between inputs and outputs of the system" [4]. After the information inputs have been analyzed by the specialized lower order formations of the brain, they will be later directed to the higher formations. D. Armstrong argues that mental states come to consciousness after the monitoring of neuropsychic processes by a higher internal sense. This inner sense could be represented by the inner perception and the current states of the brain.

The theory of global space was developed by B. Baars, who states that the emergence of a new problem or the need for a difficult choice when the brain does not have an algorithm to solve it, imposes the need for more space for processing that information. It has been shown by using an electroencephalograph that when an event becomes conscious larger areas of the brain are activated. In the vision of B. Baars, the brain has a very intense activity, 
and the given activity is represented by the working memory and the totality of the information that circulates at a certain moment in the brain.

The essential problem in the theory of higher order perception and thinking, as well as in the theory of global space, is that of the decision-making mechanism: who and when enters the scene of consciousness. One of the explanations is that in order for information to enter the sphere of consciousness it must persist for a certain time. But even if the information persists, we are not sure that it could enter the consciousness. There is a lot of information that persists for a long time without entering the consciousness. There is probably a "competition" that ensures the entry into consciousness of only that information that wins the competition.

G. Tononi, a specialist in Neuroscience, developed the theory of information integration and developed it rigorously with the help of a mathematical theory, which states that consciousness is the result of a process of integration of received information. By integrating the information received from inside and outside the body, a very concentrated information is reached. In this sense we can distinguish a priori information, a posteriori information and actual information. Tononi uses a "fi" mathematical function that measures the amount of information embedded in a system and assumes that it is related to consciousness. In the human brain, a high level of information integration requires a high degree of consciousness. As we reach simple organisms (worms, microbes, particles) the amount of "fi" decreases the degree of integration of information decreases, so the level of consciousness decreases, but this is different from zero. In Tononi's theory, the level of consciousness will always be nonzero. In fact, a fundamental law of consciousness is proposed by the theory of integrated information: a high level of "fi" presupposes a high level of consciousness. Thanks to this law that dominates the science of consciousness, it has been possible to integrate a range of scientific data. It is important to emphasize that integrated information is presented as a whole, which cannot be broken down into its component parts. Integrated information depends on the received information, but also on the structure, architecture of the brain that must perform the integration process.

\section{Quantum and structural-phenomenological perspective in consciousness research}

The nature of consciousness, the mechanism by which it appears in the brain and its supreme place in the universe are analyzed by St. Hameroff, from the perspective of quantum mechanics. He argues that the potential features of quantum calculus could explain the enigmatic aspects of consciousness. The model proposed together with Penrose (reduction of orchestrated objectives "Orch OR") suggests that the microtubules act as quantum processing units, and the individual dimers of the tubulin form computational elements. Quantum overlap and quantum computational form occur in microtubules, which represent cylindrical protein networks of the cell cytoskeleton in brain neurons. According to Hameroff, "microtubules couple and regulate synaptic functions at the neuronal level" [5]. At the same time, the "Orch OR" theory supports the reduction of the quantum overlap of microtubules to the classical output states that occur due to an objective factor called the "quantum gravity threshold" of Penrose-Hameroff. It results from instability in Planck-scale separations in space-time geometry. The output states that follow this theory are neither totally deterministic nor random, but are influenced by a noncomputable factor, rooted in fundamental space-time. Having a modern panpsychist vision, the "Orch OR" model describes 
consciousness as brain activity related to fundamental waves in space-time geometry (Riemannian geometry).

One of those who pointed out the priorities of the theme of consciousness in science is $\mathrm{D}$. Chalmers. He showed that consciousness is related to attention, introspection, reflection, voluntary control of our actions and the process of knowledge. Consciousness is what gives meaning to life, but also the most mysterious phenomenon in the universe. This is the subjective experience of the mind, and in order to integrate it into science, radical ideas are needed. Chalmers argues against skeptics who claim that there can be no science of consciousness, because consciousness by its nature is subjective.

The twentieth century was dominated by the conception of an objective science. Psychologists have objectively studied behavior, neuroscience has objectively studied the brain, but the phenomenon of consciousness has been left out of research. The recent successes, says Chalmers, also contain essential limitations. The main concern of the science of consciousness has been to look for correlations between certain areas of the brain and certain states of consciousness, but this remains a science of correlations, but not of explanations. This problem of "correlations" approached by neuroscientists is called by Chalmers the "easy problem" of consciousness. Chalmers' argument is based on the fact that this problem does not address the real enigma that would explain why physical processes are accompanied by consciousness; why there is subjective experience. This is called the "difficult problem of consciousness", and to solve it requires a scientific theory of consciousness.

Chalmers argues that existing reductionist theories, expressed in physical and neurological terms, provide information about the functioning, structure, and dynamics of the brain as a system, which determines behavior and explains how we function. However, this does not explain the subjective experience, which comes from within. Contemporary science of consciousness is a chain of explanations: Physics explains Chemistry; Chemistry explains Biology, and Biology explains parts of Psychology. On the one hand, consciousness is a real fact, on the other hand it is not clear how to integrate it into science. One of the radical ideas that would facilitate the scientific research of consciousness is that consciousness is a fundamental phenomenon, as are time, space or mass. A similar situation, Chalmers argues, existed in Physics when in the 19th century Maxwell introduced the notion of "electric charge" to explain the phenomenon of electromagnetism. Postulating consciousness as a fundamental element would pave the way for the scientific study of consciousness.

Another radical idea, according to Chalmers, refers to consciousness as a universal element. "Any system could have a certain degree of consciousness" [6]. This conception is called panpsychism, according to which not only man possesses consciousness. This, Chalmers argues, is the most effective way to reveal the fundamental laws that link consciousness to physical processes and information. Wherever there is information processing, there is consciousness. Panpsychism could change the relationship with nature by asking questions about the consciousness of other systems, such as computers, and this can have serious ethical and social consequences. rom a panpsychic informational perspective, once computers process and integrate complex information, then they possess consciousness. If this is the case, then there are serious problems with the development of intelligent information systems. So, according to Chalmers, the panpsychist perspective will pave the way for a scientific theory of consciousness. Understanding consciousness is the true key to understanding the universe and oneself. 
The position that criticizes the presuppositions of current science regarding the understanding of consciousness is presented by Mihai Drăgănescu, protagonist of the Romanian school in the fields of cognitive sciences, Al, philosophy of mind and consciousness. He elaborated fundamental works, created perspectives and new ontological and epistemological orientations in philosophy. The combination of research in quantum physics, computer science, Al, cognitive sciences and psychology places Mihai Drăgănescu among researchers in the field of philosophy and cognitive science, who put forward an original structural-phenomenological conception of consciousness.

So far, no definition of consciousness has been reached, on which there is a broad consensus. The greatest successes, according to $M$. Draganescu, were obtained by Neurobiology, which studies consciousness as an activity of the brain and, therefore, from the perspective of its neural structure. Neurology claims that consciousness is an emerging property of interconnected neural networks and advances the RNA model. In this model, selfawareness or the self-referential nature of consciousness cannot be explained. According to M. Drăgănescu, Neurology has a long way to go until the neuronal level of consciousness is fully clarified. And, explaining consciousness based only on the neural level will be very difficult, if not impossible. "Neurology will approach the reality of mental phenomena if it evolves from structural biology to a structural-phenomenological neurobiology" [7].

Mihai Drăgănescu discusses the structural-phenomenological theory that follows the direction of Penrose-Hameroff and that seeks a deeper level of matter than the quantum one. He supports the concept of "infomaterial" which is a subquantum reality capable of substantiating a viable theory of the brain with phenomenological properties. Another original idea in structural-phenomenological theory is the "phenomenological meaning" which is a fundamental and general property of nature. And at this deeper level, nature has in it something complementary yet unknown. Clearly, existence is not dual, it has a fundamental complementarity, and complementarity can be a general ontological law" [7].

Mihai Drăgănescu founds the structural-phenomenological theory that seeks to explain consciousness as a form of the mind determined by a subquantum level. He argues that quantum theory is not the final theory in science, because quantum phenomena are generated from a deep underlying reality, which has its own laws, including those of generating a quantum world, with space, with time, which generates the last elementary particles and which allows phenomenal information to intervene.

\section{Conclusion}

Although, intuitively, consciousness is a phenomenon given in a direct form, however, it remains the most mysterious and the most difficult element to define in the universe. Consciousness is the hard core of contemporary science, a nut that cannot be broken with current concepts and methods. The explanatory gap is determined by the impossibility of objective science to explain feelings, the subjective nature of consciousness. This cognitive "niche" orients contemporary inter and multidisciplinary research toward examining the fundamental, universal, and intrinsic nature of consciousness. Despite the difficulties, science has achieved certain successes determined by conceptual tendencies: the materialist monism for which consciousness is an epiphenomenon of the brain; the Cartesian dualism that supports the existence of a spiritual component of the mind and the quantum and phenomenological perspective that affirms the need for an interdisciplinary approach that 
supports the existence of a subquantum reality capable of substantiating a viable theory of consciousness with phenomenological properties.

\section{Acknowledgments}

This paper work was presented at the International Conference on Electronics Communications and Computing, IC ECCO, 21-22 October, 2021, Chisinau, TUM.

\section{References}

1. Penrose R. Shadows of the Mind: a search for the missing science of consciousness. New York: Oxford University Press, 1994.

2. Penrose R. The Road to Reality. New York: Random House, 2011, pp.102-103.

3. Searle R. J. The mind. Brief introduction to the philosophy of mind, Bucharest: Herald, 2013, (in Romanian).

4. Dennet D. C. Consciousness Explained, London: Penguin Books Ltd., 1993.

5. Hameroff S. Ultimate Computing: bimolecular Consciousness and nanotechnology. Arizona: Elsevier Science Publishers BV, 1987.

6. Chalmers D. Philosophy of Mind: Clasical and Contemporary readings. New York: Oxford University Press, 2002.

7. Drăgănescu M. Society of Consciousnes. Bucharest: Research Institute for Artificial Intelligence of the Romanian Academy, 2007, (in Romanian). 